\title{
Etnografiando negociaciones, acuerdos y alianzas entre políticos provinciales y ONG en el noroeste argentino
}

\section{The ethnography of negotiations, agreements, and alliances between provincial politicians and NGO in northeast Argentina}

doi: http://dx.doi.org/10.32870/

espiral.v23i65.607

\section{Resumen}

Este artículo explora las negociaciones, acuerdos y alianzas entre políticos y organizaciones no gubernamentales (ONG) en la región del chaco salteño. Se parte de una investigación centrada en procesos de participación de los pueblos indígenas de la región, $y$, específicamente, de la descripción etnográfica de un evento realizado en la Mesa de Tierra, espacio de organización zonal donde confluyen ONG, dirigentes de comunidades y organizaciones indígenas y criollas, funcionarios estatales, y otros. El objetivo es describir las relaciones que entablan ONG con políticos provinciales, y el rol de estos como apoyo al desarrollo local. Se concluye que estas relaciones promueven negociaciones, acuerdos y alianzas, en particular con partidos políticos.

Palabras clave: organizaciones no gubernamentales de base religiosa, partidos políticos, políticas de desarrollo, chaco salteño, Argentina.
Natalia Castelnuovo Biraben*

\begin{abstract}
This article explores the role of the negotiations, agreements and alliances between politicians and non-gobernamental organizations in the chaco salteño region. It derives from an investitagion focused on the processes of participation of the indigenuos populations of the region, and, specifically, from the ethnographic description of an event placed in the Mesa de Tierra, place of zonal organization where NGO, community and indigenous and creole organization leaders and state functionaries, among others, coalesce. The objective is to describe the relationships established between NGO and provincial politicians, and the role of the latter as support to the local development. It concludes that these relationships promote negotiations, agreements, and alliances, in particular with political parties.
\end{abstract}

Keywords: Non-governmental religious organizations, political parties, development policies, chaco salteño, Argentina.

\footnotetext{
- Investigadora Asistente del Consejo Nacional de Investigaciones Científicas y Técnicas (CONICET) de la Sección de Antropología Social del Instituto de Ciencias Antropológicas, Filosofía y Letras de la Universidad de Buenos Aires (UBA). naticastelnuovo@hotmail.com
} 


\section{Introducción ${ }^{1,2}$}

En el chaco salteño, y más específicamente, en la localidad de Embarcación del departamento General San Martín, organizaciones no gubernamentales (ONG) locales de credo religioso, indígenas y criollas se congregan una vez por mes en la Mesa de Tierra del Norte de Salta (la Mesa) para debatir sobre diversas problemáticas que les afectan. En julio de 2013, cuando participamos de una de esas reuniones, la emergencia hídrica decretada por el Gobierno provincial era uno de los temas de preocupación de los habitantes de la zona. La existencia de pozos someros en varias comunidades y las máquinas desalinizadoras de algunos pueblos resultaban insuficientes frente a la sequía que desde hacía meses azotaba la región. La importancia que este asunto tenía para los pobladores, sin embargo, cedió paso a otros temas en torno a los cuales giró el encuentro.

Si bien el temario se compuso de un abanico de tópicos, fue uno el que acaparó la atención de los integrantes de las organizaciones: la visita y entrevista con una senadora nacional provincial. Su presencia en la Mesa en tiempos de campaña electoral generó distintos y contradictorios sentimientos entre los asistentes. Así, mientras algunos estaban en desacuerdo con su presencia y consideraban que era necesario "limitarla", otros, desatendiendo los criterios consensuados por la Mesa, consideraban importante abrir este espacio organizativo a los partidos políticos. Para algunos, su figura evocaba un modelo de desarrollo extractivista

I. Expreso mi agradecimiento a los integrantes de Tepeyac, Fundapaz y la Mesa de Tierra por abrirme las puertas y confiarme sus experiencias. Agradezco muy especialmente a María H. Barroso y Mauricio Boivin por sus significativos aportes al texto.

2. La investigación fue financiada por el proyecto UBACyT "Procesos políticos, relaciones personales, e instituciones estatales. Análisis etnográfico y comparativo de la producción social de distintos niveles de organización político-administrativa" (20I4-20I I), dirigido por M. Boivin.

\section{6}


y de exportación ${ }^{3}$ impulsado por ciertos políticos provinciales vinculados a su trayectoria. Otros, en cambio, tomaban su visita como una posibilidad de concretar "alianzas" que incidirían positivamente en el rumbo de las políticas de desarrollo, y que serían capaces de crear las condiciones adecuadas para revertir una larga historia de invisibilización y olvido.

Ahora bien, ¿qué tipo de negociaciones, acuerdos y alianzas se estaban concretando para algunas de las ONG a partir de la visita de la senadora? ¿Qué intereses se ponían en juego para los actores involucrados? ¿Qué sentidos le dieron los integrantes de la Mesa a su presencia? Con miras a responder estas preguntas, en el presente trabajo se describen y analizan las actuaciones, los posicionamientos y las interacciones que tuvieron lugar en dicha visita.

El hecho de focalizarse en este evento ${ }^{4}$ se vincula con la posibilidad de avanzar con el estudio de procesos de participación política de los pueblos indígenas del noroeste y el rol de las ONG como intermediarias entre organizaciones y comunidades indígenas y criollas, y agencias gubernamentales y de cooperación internacional (Castelnuovo, 2015). Para analizar los sentidos asociados por los actores a su visita, nos focalizamos en el posicionamiento que adoptaron durante el encuentro dos de las organizaciones de desarrollo confesionales: Tepeyac, fuertemente vinculada al Equipo Nacional de la Pastoral Aborigen (ENDEPA) y la Fundación para el Desarrollo en Justicia y Paz (Fundapaz).

En este sentido, los datos que se utilizan provienen del empleo de las técnicas de observación participante y de entrevistas antropológicas realizadas a integrantes de dichas

3. La agricultura extractivista agroexportadora de la provincia se especializa primero en el cultivo de poroto y luego en la soja (Camardelli y Salazar, 2013). 4. La estrategia narrativa incluye situaciones e interacciones que se dieron en otras reuniones de la Mesa, considerando que estas aportan a la comprensión y argumento del trabajo que aquí se presenta. 
organizaciones en el marco de distintas campañas de trabajo de campo durante los meses de junio y julio de 2012, y mayo y julio de 2013. Además, se realiza una breve presentación de las trayectorias de estas dos ONG que permite dar cuenta de algunos aspectos vinculados a cómo se relacionan con los políticos provinciales y el rol central de estos últimos como apoyo y vehículo de intereses asociados con el desarrollo local.

En última instancia, las alianzas que suceden a las negociaciones y los acuerdos ponen de relieve las múltiples estrategias que adoptan las ONG en su búsqueda de incidir en el desarrollo local. Se entiende que las negociaciones son un primer paso hacia la definición de acuerdos y, posteriormente, la creación de alianzas, ${ }^{5}$ definiendo a esta última como la acción voluntaria de aliarse en función de acuerdos respecto a uno o varios objetivos compartidos.

El presente trabajo se inserta en una línea de estudios que, siguiendo a Balbi y Rosato (2003), se proponen comprender procesos políticos no sólo atendiendo a la especificidad de lo político, sino además teniendo "en cuenta los múltiples modos en los cuales lo político, lo económico, lo religioso, etc., se entrecruzan e interpenetran con el efecto, en todo caso, de conformar lo especifico de la política" (Balbi y Rosato, 2003, p. 16).

\section{El contexto regional y los vaivenes} de la política provincial

En la región del chaco salteño y la zona de transición conocida como selva tucumano-oranense, la permanencia de ONG desde fines de la década de los ochenta hasta la actualidad se comprende, en cierto modo, si consideramos

5. La noción de alianza se encuentra entre ese listado de términos que, según Liester (2000), adquirieron gran relevancia en la búsqueda de construir puentes entre instituciones de desarrollo, pero cuya claridad de significado es poca.

\section{8}


el recrudecimiento de las políticas productivistas adoptadas por el Gobierno provincial salteño. Estas políticas se materializaron a través de medidas - por ejemplo, la desafectación de áreas protegidas- que han venido favoreciendo los intereses y las alianzas con el sector económico empresarial. Es interesante notar que estas políticas productivistas que se van consolidando con el avance de la frontera agraria se anclan en un discurso que, tal como señalan varios analistas de la región (Buliubasich y Rodríguez, 2013; Camardelli y Salazar, 2013), pregona un desarrollo en términos económicos: la producción de poroto primero, y soja después, y la ganadería empresarial. La consolidación de este modelo de desarrollo extractivista como única vía para el crecimiento, el progreso y el desarrollo provincial (cuantificado en exportación de recursos naturales, inversión y generación de fuentes de empleo) trajo aparejada la intensificación de reclamos territoriales por parte de comunidades indígenas $\mathrm{y}$ familias de ganaderos criollos ${ }^{6}$ (conocidos como puesteros criollos), que pusieron en evidencia los incumplimientos en materia de derechos, en especial aquellos vinculados a la Ley Nacional N²6.160/06 -y su prórroga N²6.554/09de Emergencia en Materia de Posesión y Propiedad de las Tierras que Ocupan las Comunidades Indígenas, y a la Ley $\mathrm{N}^{\circ}$ 7.543/08 de Ordenamiento Territorial de Bosques Nativos, que prohíbe la tala y los desmontes.

Las contradicciones de la política provincial se vuelven aún más palpables cuando se advierte que parejo al desarrollo de un discurso que coloca a los políticos provinciales como "protectores" de los recursos naturales y "amigos" de los pobladores, se registran los mayores índices de deforestación y de violencia estatal hacia los pobladores por medio de desalojos (Schmidt, 2014). Los miembros de las

6. A diferencia del reclamo territorial indígena, que se funda en su uso comunitario y ancestral, apelando a la propiedad colectiva, los pobladores criollos lo hacen de forma individual y basándose en la ley veinteñal. 
comunidades indígenas y las familias criollas que se vieron afectados por este tipo de medidas encontraron apoyo en sus luchas por parte de ONG con base en la región, teniendo además muchas de estas una larga trayectoria vinculada al trabajo "misional": la evangelización de los indígenas y criollos.

Estas primeras formas de interactuar entre unos y otros se irían complejizando al punto que muchas de estas instituciones religiosas encontrarían una forma de dar continuidad a su trabajo bajo la rúbrica de las ONG, lo cual supuso entre otras cosas la incorporación de prácticas y lógicas asociadas a proyectos de desarrollo. En su relacionamiento con agencias y programas estatales y comunidades indígenas y campesinas, estas instituciones se fueron posicionando como intermediarias, definiéndose en distintos momentos, y según sus interlocutores, como instituciones acompañantes o de ayuda o desarrollo.

Si bien no es la intención de este trabajo realizar un análisis de la historia regional, se considera que ciertos aspectos vinculados a los procesos económicos y sociales son fundamentales para comprender de qué forma comunidades indígenas y familias criollas pasaron a convertirse en el foco de atención de los agentes de desarrollo local.

Desde fines del siglo XIX y principios del XX se dieron en la región varios procesos económicos que atrajeron mano de obra indígena de distintas regiones, como fue la producción azucarera, jugando un papel destacado en la reconfiguración del paisaje local. Los flujos migratorios que se dieron en la región también estuvieron vinculados con la explotación maderera y las actividades ligadas al petróleo y gas. Estos emprendimientos económicos vinculados al desarrollo regional y provincial fueron un polo de atracción para personas de distintos pueblos indígenas (incluso del sur de Bolivia y Paraguay, según Langer -2008-), y para miembros de familias criollas empobrecidas de varias provincias del 
noreste que vieron allí una posibilidad de contar con una fuente de trabajo estable.

Con este tipo de migraciones laborales (sumadas a las que vinieron de la mano de la producción agrícola, principalmente de hortalizas y porotos) se fue creando una bolsa de mano de obra indígena disponible que terminó asentándose en la zona y constituyendo el actual mosaico de pueblos indígenas ${ }^{7}$ y no indígenas que da forma a los departamentos General San Martín, Rivadavia y Orán. No es casualidad que sean estos departamentos donde las organizaciones no gubernamentales han encarado un trabajo focalizado en los pueblos indígenas y familias criollas.

Las políticas indigenistas provinciales de Salta no sólo no han resuelto la situación de irregularidad jurídica en la que se encuentran los pueblos y comunidades indígenas en cuanto a sus derechos territoriales, sino que la han agravado ${ }^{8}$ recreándose en su implementación un estilo de gobernabilidad clientelar orientado a funcionar como analgésico de dicha población. Tal como señala Carrasco (2005), resumiendo casi dos décadas de políticas indigenistas: "si hasta 1983 el político salteño había negado cualquier especificidad étnica y cultural en su población, [...] en 1998, en cambio, bajo una retórica aggiornada a una política de reconocimiento, en boga en el mundo, la diferencia se vuelve repentinamente un valor a resaltar, indigenizándose al ciudadano 'aborigen”' (p. 213). La adopción del discurso de reconocimiento basado en la diferencia cultural aparece como una medida cosmética que invisibiliza prácticas de cooptación y clientelismo.

7. En el departamento San Martín conviven miembros de los pueblos chané, chorote, chulupí, guaraní, tapiete, toba, wichí y kolla.

8. Ver: Carrasco (2005) y Rodríguez Mir (2006), y sus denuncias a la política indigenista salteña. 


\section{La Mesa de Tierra: un espacio de concertación y disidencia}

Las reuniones de la Mesa se realizan en las inmediaciones de la iglesia cristiana San Roque, en Embarcación, lugar donde confluyen los integrantes de las organizaciones que llegan desde distintos puntos de la provincia. En nuestro caso, viajamos al sitio en el mismo vehículo en el que se trasladaban una de las integrantes de Tepeyac y el párroco de Morillo, que representa al equipo de la pastoral aborigen de la diócesis de Orán. Durante el trayecto que recorrimos juntos, pudimos advertir el malestar que provocaba en uno de ellos la inminente visita a la Mesa de la senadora Sonia Escudero, ${ }^{9}$ una política con una intensa labor partidaria dentro del Partido Justicialista salteño. ${ }^{10}$ Entre las razones para dicha molestia estaba el hecho de que su invitación no hubiera sido consensuada por los integrantes de la Mesa. Al contrario, en la última reunión, la Mesa había acordado que no se le daría participación. Según comentó la integrante de Tepeyac, cuando Fundapaz propuso hacer una reunión con la senadora en paralelo a la reunión de la Mesa, el sacerdote, por temor a que esta se vaciara, aceptó la propuesta, lo cual fue moralmente sancionado por los directivos de Tepeyac, quienes desaprobaron su forma de comportarse.

9. Con excepción de los nombres de funcionarios públicos y autoridades eclesiásticas, los nombres propios de personas entrevistadas fueron modificados, colocándose en reemplazo seudónimos para mantener su anonimato.

10. En 1996, durante la gobernación de Juan Carlos Romero, Sonia Escudero ocupó el cargo de secretaria general del gabinete del Ejecutivo provincial. En 200 I, actuó como senadora nacional, siendo reelecta en 2007. En este rol presentó veinte proyectos de ley que se convirtieron en leyes nacionales, siendo las más significativas para la Mesa la Ley 26.103 de Suspensión de Remates y Emergencia Habitacional; las leyes 25.8I I y 26. 129 de Restitución de Tierras para Comunidades Indígenas; y las leyes 26.160 y 26.894 de Garantía de Propiedad de Tierras a Comunidades Indígenas. En 2015 se presentó como gobernadora por el Frente Popular Salteño, partido que tiene entre sus principales dirigentes a J. Carlos Romero. 
Por medio de la convocatoria de Fundapaz, la Mesa se abrió a la presencia de la senadora y a algunos otros dirigentes allegados que se encontraban fuera de las organizaciones que conforman este espacio. Como se intentará mostrar a continuación, esta antesala fue central para poder atender a las interacciones y distintos posicionamientos desplegados entre los actores que representaban a ambas organizaciones.

La Mesa de Tierra está conformada por una diversidad de organizaciones locales entre las cuales se encuentran las ONG Fundapaz, Tepeyac y Asociana. Estas organizaciones orientan sus acciones a familias criollas y miembros de comunidades indígenas ubicadas en los alrededores de la ruta nacional número ochenta y uno, la ochenta y seis, y el río Pilcomayo.

El término "instituciones acompañantes" lo utilizan en una marcada oposición al ejercicio de un rol de "representantes" de estas poblaciones, una noción que pone el acento en la existencia de relaciones de poder. En cambio, la idea de que son "acompañantes" pretende acentuar su carácter "consensuado" y los intereses compartidos, tal como el de reclamar tierras, frenar desmontes y poner límites a desalojos.

En la Mesa de Tierra también participan la organización zonal Wichi Amtée de Rivadavia Banda Sur, la Asociación de Comunidades Aborígenes Lhaka Honhat del Pilcomayo, la Federación Aba Guaraní de Orán, el Consejo de Organizaciones Wichi (COW) Zona Bermejo de Embarcación, la Organización Zonal Wichi T'chotLhamejenpe de Los Blancos-Morillo, y la Organización de Familias Criollas (OFC) del Pilcomayo.

La identificación de intereses comunes fue lo que los llevó a constituirse como la Mesa de Tierra, un espacio organizativo de intercambio, debate y reflexión fundamentalmente sobre la tierra-territorio, los recursos naturales y las políticas de desarrollo asociadas a estos. Esto aparece bastante 
bien reflejado en el temario que estableció el coordinador, el párroco italiano, en la víspera de la visita de la senadora. Había que debatir los temas, pero tan importante como esos debates era la posibilidad de alcanzar "consensos", por ejemplo, en relación a la declaración de la Mesa que entregarían a la senadora:

Tenemos que establecer los criterios para la reunión. Esta es una reunión de la Mesa. El encuentro con la senadora es importante, pero no debe cooptar la reunión. Tenemos que consensuar una propuesta. Tenemos el borrador que hizo la hermana Carmen de la declaración de la Mesa de Tierra y que vamos a plantearle a la senadora. Temas como proyectos de pozo [de agua] que sean para otro momento. [Que no suceda] como le pasó al obispo que cuando llegó a Los Blancos, la gente le pidió camisetas [deportivas para un campeonato de fútbol] (registro personal de trabajo de campo, 2013a).

Los miembros de la Mesa tenían varios asuntos por tratar: evaluar los fondos disponibles del proyecto Misereor con los que financian las reuniones, ${ }^{11}$ tomar conocimiento sobre la situación del juicio presentado por los desmontes ilegales en la zona (vinculado al ordenamiento territorial de bosques nativos), informarse sobre los efectos de la Ley provincial N 7658 que creó el Programa de Regularización Dominial y Asistencia para Pequeños Productores Agropecuarios y Familias Rurales, analizar distintas propuestas a la reforma del Código Procesal Civil y Comercial de la Nación, etc. Sin embargo, de todos estos asuntos, lo que más les preocupaba era la visita de la senadora. Por un lado, esto tenía que ver con que su presencia en la Mesa no se correspondía con ese supuesto "consenso" que orienta las acciones de sus

II. El proyecto lleva la firma del obispo de la diócesis de Orán, dependiendo su aval, en este sentido, de la afinidad con las reivindicaciones de la Mesa. Misereor es el nombre del proyecto episcopal de la Iglesia católica alemana para la cooperación al desarrollo. 
miembros, causando un especial recelo por parte de los miembros de Tepeyac y Asociana. Por otro lado, esto se relaciona con el profundo temor que evoca la figura de políticos, temor fundado en un recurrente uso de prácticas de cooptación política en pos de conseguir adhesiones para su partido.

A este último aspecto se refirió el cura cuando solicitó limitar su presencia y buscar por todos los medios evitar que cooptara la reunión. En este sentido fue que resaltó la importancia de que la demanda de proyectos, como había ocurrido en otras oportunidades, no los desviase de lo que era el objetivo del encuentro con la senadora. El párroco rememoró los orígenes de la organización, en un contexto en el que los intereses que llevaron a las ONG a trabajar mancomunadamente parecían diluirse:

La Mesa viene desde 2008 con antecedentes sobre tierra. Hay planteos grandes que repercuten en San Martín, Santa Victoria, Rivadavia y Orán. Debemos circunscribirnos a esos planteos, y luego dejar que cada institución pueda tener su política [...] un criterio de la Mesa es mantener las decisiones que tomamos (registro personal de trabajo de campo, 2013a).

Los miembros de Tepeyac y Asociana establecían una tajante diferencia y ponderación entre una percepción de la política, en un sentido amplio del término, definida como visión de la realidad, y de hacer política, de la que pretendían tomar distancia por sus connotaciones con las prácticas de la política partidaria tradicional, y en especial las clientelares.

Las instituciones "acompañantes" y organizaciones criollas e indígenas vienen desde hace más de ocho años reivindicando derechos territoriales, y se han movilizado en la búsqueda de acceder a una vida digna para los pobladores de la región, que incluye tanto cuestiones relativas a lograr establecer precios competitivos para la producción ganadera de los puesteros criollos en el mercado provincial 
y regional, como la definición de políticas medioambientales de preservación y cuidado del bosque nativo.

La preocupación e interés común por encontrar soluciones a un conjunto de problemáticas los llevó a reunirse una vez al año, a fines de agosto, en el marco de las celebraciones por la fundación y fiesta patronal de San Ramón de la Nueva Orán. Durante la homilía que pronunció el obispo, se retomaron muchas de las demandas de la Mesa sobre la problemática de la tierra, buscando impactar en las máximas autoridades políticas que asistieron al evento. Desde su creación, estos grupos han contado con el apoyo y compromiso de diversos obispos de Orán: monseñores G. Sueldo, Lugones y Marcelo Colombo. La percepción por parte de las organizaciones acompañantes, criollas e indígenas, así como de dirigentes comunitarios indígenas, de que los problemas que vivían debían ser tratados con mayor profundidad, los llevó a plantear la necesidad de reunirse de forma más periódica, dando así origen a la Mesa de Tierra en el año 2008. Según una de las promotoras de Fundapaz, quien además integra el equipo diocesano, lo que los había unido era "la necesidad de hacer cosas juntos por la tierra; todos los que venimos sufriendo por todo lo relacionado con ella" (registro personal de trabajo de campo, 2013b).

El objetivo de la Mesa era entregar a la senadora la declaración, un documento que era visto por la organización como una interpelación al Estado para que asumiera su "rol" de garante de derechos reconocidos, haciendo "posible la materialización de[1] derecho a la tierra en áreas fiscales y privadas" (Declaración de la Mesa de Tierra, 2013, p. 1). El documento contenía denuncias por desmontes ilegales, y mencionaba que era de conocimiento público que esto violaba la Ley 26.160 de Relevamiento Territorial. Además, solicitaba conocer las implicancias de algunos proyectos de ley que estaban siendo discutidos a nivel nacional; exigía contar con información sobre el Fondo de Reparación 
Histórica, desde el cual la provincia estaba proyectando y ejecutando grandes obras de infraestructura, sin llevar a cabo una consulta previa e informada en las comunidades afectadas; además, reclamaba políticas ambientales adecuadas y mecanismos de control ciudadano para casos de incumplimiento de leyes.

Con estas y otras puntualizaciones, el documento buscaba poner luz sobre la distancia existente entre la normativa que plantea un reconocimiento de derechos y su efectiva aplicación, responsabilizando a los políticos por la falta de decisión y gestión en la entrega de títulos de tierras a comunidades indígenas y familias criollas.

La senadora recibió el documento porque, como expresó uno de los integrantes de la Mesa, ella era vista como una representante del pueblo que tenía la posibilidad de cambiar la historia, en el sentido de hacerse eco de la deuda histórica del Estado con el pueblo indígena. La senadora agradeció la invitación y procedió -como buena política- a exponer su logro durante sus gestiones: la sanción de leyes contra proyectos de expropiación y de regulación dominial. Vinculó su trayectoria política a la figura del exgobernador Juan Carlos Romero. Evaluó que las gestiones de títulos en el caso de tierras fiscales eran un asunto fácil de resolver, reduciéndolo a una cuestión de meras voluntades entre las partes, que debían encontrar el momento para "sentar[se] (con el Estado) y resolver[lo]" (registro personal de trabajo de campo, 2013c). Consideró que la normativa había dejado desprotegido al sector criollo, y que esto favorecía los desalojos realizados en pos de los commodities y la soja. Además, mencionó que este punto figuraba en su proyecto a la reforma del Código Civil, un proyecto que deseaba se enriqueciera con los aportes de la Mesa.

Cuando la senadora se despidió, los miembros de las organizaciones dejaron sus asientos para formar pequeños grupos con el fin de intercambiar opiniones sobre lo ocurrido. 
Se escuchó entonces que una de las integrantes de Asociana comentaba con una de Tepeyac: "Fundapaz rompió con lo que se había pactado. Hay una responsabilidad que tenemos como organizaciones. Nosotros podemos tomar distancia de la propuesta de Escudero, pero la gente no siempre lo hace ni piensa así" (registro personal de trabajo de campo, 2013d). Fundapaz había ido claramente en contra de los códigos, y de ahí las críticas a su comportamiento.

Sin embargo, tanto o más grave que lo anteriormente señalado eran los efectos impensados de la visita de la senadora. Lo impensado tiene que ver precisamente con aquello señalado por las integrantes de Fundapaz y Asociana respecto a poder tomar distancia, especialmente cuando la figura de la senadora evocaba intereses de sectores políticos y económicos que se oponían a los que defiende la Mesa: "Ella fue parte del Gobierno de Romero y hoy él es uno de los grandes terratenientes de la zona. Habría que haberle dicho esto" (registro personal de trabajo de campo, 2013e).

Para los integrantes de Fundapaz, su vínculo con los partidos políticos era una forma de posicionarse en el escenario provincial y nacional, de crear puentes con agentes estatales nacionales, de participar en la formulación de leyes destinadas a mejorar las condiciones de vida de las poblaciones indígenas y familias criollas, de vehiculizar reivindicaciones y lograr visibilidad como actor político:

La Mesa está para hacer incidencia pública. Sí me parece que es función de la Mesa hacer incidencia política. Es parte de la acción que hay que hacer. La Mesa está aislada del debate nacional. El tema es ¿cómo se articula a nivel nacional? No se la escucha en ningún lado. Si está para hacer incidencia política hay que buscar una articulación nacional (registro personal de trabajo de campo, 20l3f).

A diferencia de lo que opinaba este técnico y varios directivos de Fundapaz, para las autoridades de Tepeyac la inci- 
dencia pública y política tenía menos que ver con el hecho de vincularse con políticos, y más con el resultado de una Mesa fortalecida. De hecho, la relación con los políticos era vivida como una potencial amenaza a la legitimidad de su trabajo. Esa distinción con los funcionarios políticos, que se mantiene aun en los casos que desarrollan estrategias conjuntas, es un aspecto constitutivo de la identidad de las ONG que, como apuntan Bernal y Grewal (2014), contribuyen, reforzando que ellas no son el Estado, a producir el Estado, incluso cuando proliferan en ellas formas de gobierno.

Meses más tarde de la reunión de la Mesa señalada con anterioridad, el director de Salta de Fundapaz fue nota del diario El Tribuno por su presentación como conferencista en la Universidad Nacional de Salta, en un evento promovido por la senadora y el exgobernador Romero. La noticia conmovió a los dirigentes de Tepeyac, quienes pasaron a reinterpretar lo ocurrido en la Mesa a la luz de este evento como una expresión de intereses en juego y ocultos de esta organización.

\section{Trayectorias de ONG de base confesional volcadas} a la "promoción humana"

En el chaco salteño existe una constelación de ONG con base religiosa y, en menor medida, laicas, orientadas a reivindicar los derechos de los pueblos indígenas y familias criollas desde un trabajo que se sostiene fundamentalmente a través de proyectos de desarrollo (Mendoza, 1994; Spadafora, 2005). ${ }^{12}$ Algunas de ellas nacen de "la filantropía eclesial; otras, basadas en las ideologías humanistas del

12. Estos abarcan capacitaciones y talleres sobre diversas temáticas; proyectos de infraestructura productiva y comunitaria, y su respectiva asistencia técnica y económica; proyectos en educación intercultural bilingüe y salud; encuentros y ferias de productores, de mujeres y organizaciones; gestión de personerías jurídicas; etc. 
tiempo" (De la Cruz, 1997, p. 32). Varias de estas organizaciones se fueron constituyendo en la rama social del trabajo realizado desde las iglesias cristianas.

El tipo de posicionamiento y acciones que llevan adelante y los grupos con quienes trabajan crean distintos perfiles de organizaciones "indigenistas" o "criollistas". Su principal fundamento respecto a su actuación como portavoces de estas poblaciones se basa en el hecho de que el Estado argentino viola sus derechos y cuenta con una lista de agravios realizados hacia los pueblos indígenas que incluye invisibilización y falta de reconocimiento (Gordillo y Hirsch, 2003).

En el presente apartado, se reconstruyen brevemente, a partir de los materiales obtenidos en entrevistas etnográficas, los orígenes de dos ONG de base religiosa cristiana con actuación en el chaco salteño y con fuerte injerencia en la Mesa de Tierra: Fundapaz y Tepeyac. De sus trayectorias institucionales, se hace énfasis en los intereses que dan sentido a sus acciones, y cómo estos pueden desencadenar negociaciones a las que proceden acuerdos y alianzas con políticos provinciales, autoridades eclesiásticas y agencias de cooperación. Con ello, se busca iluminar ciertos aspectos vinculados a las formas que asumen las relaciones que entablan con políticos provinciales y el rol de estos últimos como apoyo y vehículo de intereses asociados al desarrollo local.

La problemática presentada se enmarca en el campo de los estudios sobre las ONG, sociedad civil y política. Dentro de este campo, algunos se han abocado a analizar las relaciones que mantienen las ONG con agencias del Gobierno, movimientos sociales, agencias de desarrollo internacional, redes transnacionales y otras $\mathrm{ONG}$, señalando el impacto que estas tienen sobre la globalización y las vidas de aquellos asentados en las localidades. Básicamente estos estudios se dividen en dos: los de un enfoque optimista e idealista de las ONG, y aquellos otros que, incluso siendo críticos del 
desarrollo, impulsan a las ONG como una vía de alternativas a los actuales paradigmas de desarrollo.

El optimismo de los partidarios de las ONG se funda en la creencia de que hacen el bien, en tanto se encuentran al margen del mercado y la corrupción que caracteriza a la política y al Estado (Fischer, 1997, p. 442). Esta visión se asienta en el presupuesto de un accionar desinteresado y apolítico, donde las ONG representan todos esos valores que los Gobiernos no alcanzan: flexibilidad y apertura a la innovación, eficacia y rapidez para implementar proyectos, y capacidad de identificar y dar respuesta a las necesidades de las bases (Fischer, 1997).

Esta percepción llevó a que varias organizaciones se convirtieran en una importante alternativa al Estado, en especial en aquellos países donde su accionar falló o encontró limitaciones. El segundo enfoque pone de relieve su capacidad para influir a nivel moral y político, y el hecho de que se trata de actores políticos con gran potencial para generar cambios en las relaciones de poder. Este grupo de analistas valoran a las ONG por "su habilidad para politizar asuntos que no lo estaban o que eran irónicamente despolitizados por el discurso de desarrollo o la participación democrática" (Fischer, 1997, p. 445). Coincidimos, en este sentido, con que nada se aleja más de la realidad que la imagen que presenta a las ONG como actores distantes de la arena política y del mercado, cuando son, por el contrario, actores centrales en la política nacional y global.

Fundapaz inicia su trabajo en Los Blancos, Salta, en el año 1982, firmando un convenio junto al Ministerio de Bienestar Social de Salta y el Obispado de Orán (Murtagh, 2013). A diferencia de las acciones que venía llevando a cabo en Santiago del Estero con campesinos, su trabajo en esta provincia se dirigió a la población indígena. Su propuesta fue de tipo productiva, y buscaron, a través de ella, realizar una "ocupación efectiva de la tierra" (Fundapaz, 
2003, p. 18). La elección de la zona de trabajo tuvo que ver fundamentalmente con las recomendaciones que recibieron del obispo de Orán, monseñor Sueldo, con quien el grupo de monjas fundadoras mantenía un estrecho vínculo. Según recordó Martín, el ex director de Fundapaz Salta, el obispo tenía un fuerte compromiso con "los movimientos sociales" y "los más necesitados" y esto se materializó en la línea de trabajo solidario que promovió bajo el rótulo de "promoción humana" (entrevista personal, 2013h).

Las monjas fundadoras contaban con los fondos de una donación y ese fue el puntapié inicial para crear, primero, el Instituto de Cultura Popular (Incupo), y luego, en 1973, Fundapaz, ambas organizaciones sin fines de lucro de inspiración cristiana, en las que canalizaron su obra de opción por los pobres. ${ }^{13}$ Este origen común determinó cierto flujo entre las personas que integraron los respectivos equipos. El grupo pionero se conformó con varios militantes de base católicos de distintos puntos del país que, influidos por la teología de la liberación, estaban comprometidos con los sectores más pobres. Las tareas misionales enmarcadas en una obra de promoción humana que emprendieron varios de estos militantes significaron una paulatina incorporación a los equipos de personas de las propias localidades que asumieron un rol de promotoras.

Para las comunidades indígenas, su principal interés era conseguir los títulos de las tierras, y esto fue lo que les transmitieron a las monjas, quienes, haciéndose eco de su demanda, iniciaron un trabajo de fortalecimiento de las organizaciones comunitarias, en paralelo a avanzar con las respectivas gestiones para lograr la regularización y tenencia de la tierra.

13. Desde 1969, Argentina adoptó las conclusiones del Concilio Vaticano II y las de la Conferencia del Episcopado Latinoamericano, realizada en Medellín (Verbisky, 2009). 
Una gran mayoría de las comunidades de Los Blancos está asentada en lotes fiscales, por lo que fue necesario establecer diálogos con las autoridades e instituciones provinciales competentes en esta materia. Monseñor Sueldo mantenía contactos con personas que ocupaban altas esferas del poder local: tenía "llegada" al gobernador Ulloa. Para los dirigentes de las organizaciones, su papel de mediador fue central para avanzar en las negociaciones para la entrega de varios títulos de tierras fiscales. Su cercanía con el gobernador se volvió memorable para la organización en tanto significó un parteaguas en su forma de trabajo en terreno. En una de las audiencias que mantuvieron con el gobernador, este les planteó como condición para la entrega de títulos de tierras que debían armar una propuesta que incluyera a los criollos. A partir de entonces, Fundapaz dividió su equipo en dos grupos: uno que se ocuparía de la asistencia técnica al sector criollo, y otro que haría lo mismo con la población indígena. El hecho de aceptar las reglas impuestas por el gobernador tuvo, sin embargo, un impacto negativo en el capital simbólico de la organización:

Los indígenas vieron a Fundapaz como enemigo porque se fue a trabajar con aquel que representaba para ellos el enemigo: los criollos. Los criollos eran los que los humillaban, avergonzaban y discriminaban (entrevista personal, 20l3h).

Los miembros de Fundapaz reconocen las críticas provenientes de las comunidades y ONG de la zona; sin embargo, consideran que es "fácil ser indigenista solo laburando con indígenas" (entrevista personal, 2013h). En este sentido, lo que algunos le critican es visto por la organización como un rasgo distintivo y positivo: el desarrollo de una metodología de trabajo intercultural que apunta a construir lazos entre dos culturas: la criolla y la indígena. El trabajo pionero realizado con los criollos le valió a Fundapaz su reconoci- 
miento por parte de las otras organizaciones. A principios de los años noventa, y en conjunto con Tepeyac, comenzaron un trabajo de organización de grupos criollos y wichí, con miras a reclamar la entrega de los títulos del lote veintitrés al sur de Morillo.

En este proceso, la consecución de acuerdos entre ambos grupos se volvió un aspecto central de la estrategia de las organizaciones, y en especial de Fundapaz. Uno de los miembros de Fudapaz recordó que parte del trabajo supuso identificar las expresiones locales e indígenas y los sentidos asociados: "En lengua wichí, se usa el término tajlava para acuerdo y refiere a ese momento en el que se logra consenso, permitiendo entonces dar por cerrado el asunto en discusión" (entrevista personal, 2013h). La búsqueda de "acuerdos"14 fue y sigue siendo uno de los aspectos distintivos de la metodología de trabajo de Fundapaz, en tanto considera que son una vía privilegiada para alcanzar soluciones entre los actores locales.

Sin embargo, los acuerdos también eran claves en escalas provinciales, dependiendo de estos muchas veces la posibilidad de permanencia y actuación de las ONG en el territorio. A esto se refirió Martín cuando relató que fue con base en lograr acuerdos que, incluso durante un Gobierno provincial como el de H. H. Cornejo (1987-1991), que intentó por todos los medios "boicotear" su trabajo, la organización no sólo logró continuar con su trabajo, sino además "sacarle hechos políticos irreversibles", refiriéndose con ello a conseguir "acuerdos de los que el Gobierno no pudiera retroceder" (entrevista personal, 2013h).

Este proceso, que duró varios años y estuvo plagado de negociaciones entre los distintos actores involucrados, dio como resultado la firma de un acta acuerdo que fue el prole- 
gómeno del trabajo sobre los acuerdos de convivencia entre criollos e indígenas. Para llegar a los acuerdos, fue necesario pensar en potenciales situaciones de desacuerdo y conflicto sobre el territorio. El resultado de este trabajo conjunto fue una lista de veintiséis puntos de acuerdos entre "vecinos". Una promotora de Fundapaz que había formado parte de las discusiones recordó que uno de los temas sobre los que habían trabajado era cómo resolver potenciales situaciones de conflicto y desarrollar ciertas normas comunes de convivencia entre los grupos. Por ejemplo, cuando una vaca (perteneciente a una familia criolla) ingresaba a tierra indígena, o el caso de un animal que mientras era perseguido por el cazador indígena se escapaba a tierra criolla, lo que implicaba que este tuviera que saltar un alambrado para continuar la caza.

La experiencia "exitosa" en la entrega de los títulos del lote con su rol de bróker, ${ }^{15}$ luego de doce años de trabajo, atrajo la atención de Asociana. Su interés descansaba en las dificultades que estaban encontrando, desde la organización de la Asociación de Comunidades Aborígenes Lhaka Honhat, para avanzar con el reclamo de los lotes fiscales catorce y cincuenta y cinco en Santa Victoria Este. Esto desencadenó el inicio de un trabajo de Fundapaz en la región con la población criolla, que constituía la tercera parte de los pobladores que vivían en los lotes.

Como en los otros casos, la idea fue avanzar en un acuerdo entre las partes para conseguir la entrega del título de esas tierras. Fundapaz creó un nuevo equipo, centrado en la temática de la tierra, que, por las relaciones interpersonales existentes entre los directivos de las organizaciones, fue

I5. La antropología posee una vasta tradición acerca del tema de los “mediadores". Para los fines operativos del estudio, se adopta la noción de broker de Olivier de Sardan (2005), y su énfasis en aquello que tienen en común estos agentes de desarrollo: las instituciones de desarrollo que los emplean se dirigen, por medio de su agencia, a los beneficiarios de desarrollo. 
protagonizado por Hernán, el sobrino de Cristóbal Wallis, quien para ese momento se desempeñaba como el coordinador de Asociana en el Pilcomayo. El exdirector de Fundapaz reconoció que, más allá de las relaciones de parentesco, era innegable que esta persona había jugado un rol fundamental en la conformación de una organización criolla conocida por las siglas OFC, Organización de Familias Criollas.

A la organización siguió un trabajo de capacitación en derechos que incluyó a la población criolla, en tanto, como señaló Martín, "hasta ese momento parecía que sólo los indígenas tenían derecho sobre la tierra" (entrevista personal, 2013h). Martín destacó los atributos de vendedor que identificó en Hernán y que permitieron que el proyecto de la OFC lograra conseguir financiamiento internacional. Este proyecto, denominado "Pilcomayo", incluyó además a Lhaka Honhat, Asociana y Fundapaz. El financiamiento que recibieron de Pan Para el Mundo y la agencia Misereor hizo posible, entre muchas otras cosas, el alquiler de una oficina para las reuniones de las organizaciones.

Según Martín, las primeras reuniones no habían sido sencillas ya que "los criollos temblaban" (entrevista personal, 2013h) frente a los indígenas, a quienes percibían fortalecidos en términos de ciudadanos que se sabían sujetos de derechos, un discurso vinculado a las capacitaciones que Asociana realizó en la zona.

El interés por sumar a Fundapaz no era compartido por todos los miembros de Asociana. De hecho, algunos interpretaban sus acciones como una clara demostración de rechazo al derecho indígena. Esta forma de ver las cosas contrastaba con la del equipo de Fundapaz, que veía logros donde los otros percibían fracasos. Entre sus logros más significativos, señalaron el cambio de relación entre los pobladores y una actitud respetuosa de los criollos hacia los indígenas. De estos cambios habló Martín cuando contó que los criollos se habían acercado "a pedirles por favor a 
los wichi que no rompieran el acuerdo que los incluía en su reclamo" (entrevista personal, 2013h).

El valor de lo que esto supuso sólo puede comprenderse teniendo en cuenta la historia de enfrentamientos entre estas poblaciones. En el trabajo cotidiano, uno podía ser "indigenista o criollista", sin embargo, la línea de Fundapaz ponía el énfasis en trabajar con ambos grupos, considerándolo como el camino privilegiado para que se constituyeran en "socios". Esa nueva identidad como socios la adquirían con base en compartir una realidad con puntos de encuentro y apoyo mutuo. La idea de Fundapaz era no confrontar a los pobres, sino unirlos con base en la situación de pobreza material que compartían, construyendo su identidad en oposición a un "enemigo": el Gobierno. La construcción de los grupos como socios puede ser vista como un aspecto más del proceso de construcción de alianzas y acuerdos que promueve Fundapaz, tratándose en ambos casos de acciones que se inscriben como parte central de la estrategia de dicha organización.

Promover la organización de los grupos constituye la base del trabajo de Fundapaz, fundamentado en el hecho de que se trata de una condición indispensable para el desarrollo, esto según Juan Luis Díaz, actual director ejecutivo de Fundapaz (Clarín, 2013). Este desarrollo será impulsado fundamentalmente desde lo productivo: "mejora[r] y diversifica[r] los sistemas productivos locales y transforma[r] la producción primaria para su comercialización” (Clarín, 2013). Lo productivo puede además referir al manejo y la conservación de los bosques nativos, la producción y uso de pasto y, en una etapa posterior, la planificación estratégica de gestión y comercialización de sus recursos y productos. Esto se funda en una percepción por parte de los miembros del equipo de que el reclamo de tierra es tan sólo una parte del trabajo, siendo tanto o más importante que esta lograr que la gente no "termine vendiendo [la tierra] o dejando que gente entre 
a desmontar el bosque" (entrevista personal, 2013h) una vez obtenidos los títulos.

El trabajo que impulsan es criticado ${ }^{16}$ y tildado de desarrollista por varias ONG, que ven sus acciones como una expresión de una lógica mercantilista que busca convertir en empresarios a los pequeños productores. No obstante las críticas, para Fundapaz lo productivo sigue siendo una de las vías privilegiadas para promover actividades de subsistencia económica que posibiliten la construcción de vidas más dignas. Sin embargo, como bien plantea Occhipinti (2005), su trabajo se plantea alegando un propósito superior a aquel de alcanzar logros en materia de progreso económico: de lo que se trata es de alcanzar justicia social y dignidad humana.

Tepeyac, por su parte, es una organización creada a partir del trabajo iniciado en la zona desde el equipo de la Pastoral Aborigen, perteneciente a la diócesis de Orán. La conformación del equipo está vinculada a los cursos de "promoción humana" que organizó Incupo ${ }^{17}$ en Reconquista, Santa Fe, a mediados de los ochentas. Este instituto funcionó, para muchos jóvenes militantes cristianos con vocación por ayudar a lo más "necesitados", como un espacio de formación y de práctica sobre "el mundo indígena" (entrevista personal, 2013g). Desde escuelas y parroquias, y junto a misioneros, tomaron contacto desde una visión cristiana con gente pobre que, percibían, se encontraba al margen de la sociedad. Algunos de estos jóvenes fueron seleccionados por el obispo Iriarte para formar el equipo de la pastoral.

16. En ocasiones estas críticas entran en consonancia con las realizadas por la academia, que acusa a las ONG de aplicar proyectos "concibi[endo] a las diferentes aldeas como comunidades homogéneas sin fracciones, lideradas por una sola persona” (Rodríguez Mir, 20I I, p. 8).

17. Nacida en los años setenta apoyada por tres obispos que estaban en el NEA:J. J. Iriarte de Reconquista (Santa Fe), A. Devoto de Goya (Corrientes), y Di Stéfano de Roque Sáenz Peña (Chaco). Murtagh (2013) establece agosto de 1963 como el momento embrionario del proyecto Misereor, que finalmente condujo a Incupo.

\section{8}


Los obispos y los directivos de Incupo escogieron a la localidad de Morillo como el lugar donde este grupo de jóvenes desarrollaría su trabajo. En parte, esta elección se fundó en las relaciones personales que la directora tenía en la zona, donde vivía una pariente y religiosa que llevaba un tiempo trabajando con comunidades indígenas. Mabel, que fue quien asumió desde 1986 la tarea de coordinar un equipo de laicos, pertenecía a la orden de las teresianas, y sus acciones se desarrollaban en el marco de las preocupaciones y compromiso social del obispo monseñor Sueldo, quien estaba a su vez en consonancia con los lineamientos generales del Equipo Nacional de la Pastoral Aborigen (ENDEPA). Enrique, el actual director de Tepeyac, se formó con ese equipo pionero, y rememoró cuáles fueron las motivaciones que lo llevaron a instalarse en la zona:

Me quedé porque me apasionó el tema indígena, porque hay muchas cosas para hacer, hay muchas injusticias y muchas desgracias: el tema cultural, el tema de los indígenas. Cuando vos conoces al pueblo indígena, por lo menos desde la óptica que el equipo me ha permitido conocer[lo], es un tema groso, un tema gordo, digamos. Es otra mirada, otra cultura, una cuestión apasionante, y yo no tenía... no era una cuestión académica. Lo mío iba por otro lado. Sí tenía una motivación juvenil que había sido alentada por grupos juveniles dentro de la Iglesia católica. Había grupos en los años setenta que eran muy fuertes, digamos, todo este contenido de la promoción humana era muy fuerte en esa época. Y hubo mucha gente que encaró su vida desde lo profesional, desde lo familiar, de lo afectivo, poético, artístico, hacia ámbitos distintos gracias a una Iglesia que se popularizó, que es muy sudamericana. Era una línea que iba a revertir esa imagen que autoteníamos [sic] los argentinos de ser el país más europeo de América. Porque hasta los años sesenta, la Argentina era eso: era el país más europeo de América (entrevista personal, 2013g). 
El trabajo del equipo se enmarcó en las acciones de reconocimiento que a partir de 1987 promovieron las iglesias desde una visión pastoral y periférica, inspirándose en la teología de la liberación y la teología india. El trabajo pastoral se convirtió en un elemento central del equipo, en tanto, según entendían, generaba conciencia y acercaba elementos para la autodeterminación de los pueblos. Por otro lado, su tarea también tenía como norte remover ciertas representaciones discriminatorias de los indígenas como "vagos" y "sucios", aún vigentes entre los sectores más conservadores de la Iglesia y de la sociedad salteña.

La posición epistémica desde la cual emprendieron los diversos objetivos que los movilizaron fue la del encuentro de las culturas y la idea de dignidad, en tanto valor humano y espiritual fundamental. En este sentido, la dignidad personal es vista como una condición previa y necesaria al anuncio de otras noticias espirituales y de la evangelización (bautismo, comunión, catequesis, etc.). La "promoción humana" fue entonces el camino desde el cual se instalaron estos valores, orientados a un "reconocimiento de todos, como hijos de Dios, con nuestros derechos" (entrevista personal, 2013g). Dentro de este marco de reconocimiento, los derechos de los pueblos indígenas, y en especial el derecho a la tierra, se convirtieron en un pilar del trabajo del equipo, a través de capacitaciones sobre esta problemática. La "promoción humana" se articuló con algunos preceptos que provenían de la teología india, y que eran parte de los lineamientos que seguía el equipo de la Pastoral Aborigen a nivel nacional, en consonancia con lo que ocurría en La-tinoamérica a principios de los ochenta, ${ }^{18}$ en particular, con la centralidad que adquiere el sujeto indígena con base

18. Desde la pastoral indígena dentro de la Iglesia católica en toda Latinoamérica, se toma el tema de la tierra como consecuencia del impacto que tuvo en Juan Pablo II el encuentro en 1979 con indígenas en Puebla, México, que le plantearon su preocupación por el tema y la relación de este con su identidad. 
en el descubrimiento de que es sujeto de una experiencia religiosa que produce una teología distinta a la occidental.

Si bien el trabajo del equipo se enmarca en estas preocupaciones más amplias que orientan el trabajo pastoral católico a nivel latinoamericano, su accionar también se fundamenta en el hecho de que se trata de un reclamo local. En este sentido, lo que buscan resaltar es que sus actividades en torno a la problemática de la tierra y la educación se corresponden con los intereses de los propios indígenas, y no, como algunos suelen criticarles, a una ficción, en el sentido de invención de la problemática (Ferguson, 1996; Escobar, 1998).

El reclamo de tierras tiene como telón de fondo que la mayoría de comunidades indígenas de la zona aún no cuenta con los títulos de propiedad, lo cual crea el marco de condiciones que vuelve posible que las comunidades sean trasladadas y desalojadas de sus tierras. ${ }^{19}$ A esto se suman los problemas cotidianos que surgen de los distintos usos que hacen y significados que le dan a la tierra, por un lado, los indígenas y los criollos y, por el otro, las empresas extractivas que buscan instalarse, buscando convertir a la zona en un polo productivo petrolífero.

El trabajo del equipo tiene como objetivo prioritario asegurar la tierra de las comunidades por medio de obtener el reconocimiento de su derecho por parte del Estado y reafirmar la posesión. Para ello, el equipo desarrolla múltiples estrategias, siendo quizá una de las más significativas la de reafirmar la posesión a través de proyectos de infraestructura productiva y comunitaria: viviendas, salones comunitarios, pozos de agua, represas, sacha huertas, etc. ${ }^{20}$

19. Tal era el caso de una comunidad que había sido trasladada quince veces en nueve años.

20. Sacha significa "monte" o "silvestre", y es un préstamo del quechua empleado en la región. Este término se utiliza en lugar de lëlajwek, que es la palabra wichí para huerta. 
El obispado cumple un rol clave en la intermediación con diversos funcionarios y organismos estatales e internacionales para la obtención del financiamiento del cual dependen los distintos proyectos que lleva adelante el equipo. Sin embargo, su rol no se limita a los proyectos. Como mediador, también interviene en la problemática de la tierra. Monseñor Sueldo era una de esas figuras especialmente recordadas por su labor en las gestiones por la entrega de títulos de tierras de dos lotes fiscales de la zona:

[El gobernador] Romero venía todos los años a la fiesta patronal de Orán, y en una oportunidad el obispo le expresó [a Romero] que había mucha desnutrición, mucha pobreza en la zona. Dice que él se enojó y dejó de participar de la fiesta. Cuando asume Urtubey [gobernador entre 2007 y 2015], él vuelve a participar y se abre la posibilidad de llegar [al gobernador]. El obispo organiza una reunión para que los wichí le planteen su situación. En el Gobierno de Romero [1995-2007], se hizo un acuerdo para la adjudicación de tierras, y eso no se había concretado. El obispo hizo posible que los wichí se presentaran ante el gobernador y que este los escuchara (entrevista personal, 2013g).

A través de estas intermediaciones entre el obispado y políticos provinciales, el equipo gestionó los títulos de ocho lotes fiscales de propiedad comunitaria indígena wichí. Su logro consistió en haber conseguido estas gestiones antes de que otros actores "colonizaran" esas tierras. Los títulos de los grandes fiscales habían sido gestionados, quedando pendiente la entrega de lotes más pequeños, en los que se encuentran actualmente trabajando. Los primeros pasos en esta dirección, la del reclamo de las tierras indígenas, los habían dado en la década de los noventa. En aquel entonces, el equipo diocesano se coordinaba con Fundapaz, que era la encargada de organizar y fortalecer el reclamo de los criollos que residían junto a los habitantes indígenas en el lote veintitrés. En este proceso de construcción de un reclamo 
por la tierra, tanto indígenas como criollos fueron forjando sus propias organizaciones zonales. Desde sus organizaciones impulsaron sus reivindicaciones y realizaron diversos tipos de acciones políticas. Es un logro precisamente de sus reivindicaciones la medida cautelar que obtuvieron de la Corte Suprema de Justicia de la Nación que ordenó al Gobierno provincial el cese provisional de los desmontes y tala de bosques nativos.

El tipo de acciones que emprende el equipo llevó a que los agentes municipales de la localidad pasaran a identificarlos como los responsables de todo asunto vinculado a la población indígena. Tanto así que, según manifiestan a modo de crítica varios de los integrantes del equipo, en muchas ocasiones son ellos quienes con la camioneta se ocupan de trasladar difuntos del hospital regional a sus respectivas comunidades de origen donde son enterrados. Para el director del equipo era evidente que el Municipio debía ocuparse no sólo de los asuntos de la población criolla, sino además de la indígena, porque, en definitiva, como expresó, ellos no eran el Estado.

Por otro lado, en los casos en que no asumían ese rol, las críticas provenían de parte de la población wichí, que no consideraba esta explicación lo suficientemente convincentecomo para que sus necesidades fueran desatendidas. Esta forma de dar respuestas a los problemas cotidianos de los indígenas les valdría que en más de una ocasión los tildaran de asistencialistas. El equipo conocía estas críticas provenientes de las organizaciones, pero estaba decididamente más preocupado porque sus acciones no fueran vistas como paternalistas. La búsqueda por establecer relaciones de igualdad era, desde el punto de vista de la organización, una forma de evitar caer en el paternalismo basado en una supuesta autoridad y superioridad. 


\section{Reflexiones finales}

Por medio de una descripción y análisis etnográfico de las interacciones y posicionamientos adoptados por dos ONG de base religiosa que integran un espacio organizativo provincial se mostró de qué forma estos ámbitos promueven negociaciones, acuerdos y alianzas entre sectores sociales $\mathrm{y}$, en particular, con partidos políticos.

Asimismo, se puso de relieve el rol central que desempeñan los partidos políticos, ya sea como competidores o apoyando las acciones políticas de las ONG, para entender la diversidad de concepciones respecto de la sociedad civil, una observación que se vuelve relevante si tenemos en consideración el planteo de Dagnino (2011) respecto de que "la sociedad civil y el Estado son siempre mutuamente constitutivos" (2011, p. 124), siendo esta relación una dimensión clave en la construcción de la democracia. La traducción de los conocimientos de las organizaciones y los políticos en proyectos de ley y leyes es un ejemplo de los puntos que los unen, especialmente cuando, tal como señala Buliubasich (2013), es cada vez más frecuente que las demandas específicas de pueblos indígenas en Salta se encaminen por vías judiciales y, en este sentido, apelando a un discurso de derechos.

El hecho de hacer énfasis en este espacio organizativo también dejó al descubierto la existencia de distintos intereses por parte de las poblaciones indígena y criolla y las organizaciones acompañantes, que además se desempeñan en otras esferas de la vida social como agentes de desarrollo local, articulando entre programas y políticas de desarrollo estatal o internacional. El valor que las organizaciones otorgan a los intereses y a los objetivos que persiguen resulta un factor de peso en la elección de sus estrategias, lo cual se vincula con el señalamiento realizado por Mosse y Lewis (2006) cuando apuntan a la centralidad de 
la traducción como tarea distintiva de estos mediadores, cuya capacidad radica en poder traducir e interpretar las diferentes lógicas, intenciones, objetivos y ambiciones que guían a las personas e instituciones.

Por otro lado, el estudio relevó la importancia que las organizaciones otorgan a su capacidad de incidir pública y políticamente. El análisis etnográfico de la actuación de la Mesa de Tierra también puso al descubierto cuáles son las formas de acción y movilización legitimadas desde las organizaciones. Poner la mirada en las interacciones entre las organizaciones nucleadas en este espacio organizativo complejizó la reconstrucción de las trayectorias institucionales de Tepeyac y Fundapaz, en tanto permitió contrastar ciertos aspectos de esa relación en el tiempo poniendo en el centro los intereses, estrategias, lógicas y racionalidades sobre las que descansan sus acciones.

Por su parte, el análisis de las trayectorias institucionales puso de relieve el peso de las relaciones con actores de la política en la construcción de alianzas, negociaciones y acuerdos que afectan la definición de los proyectos de desarrollo local que impulsan respectivamente las organizaciones, así como las tensiones y contradicciones resultado de estas prácticas y posicionamientos políticos de las organizaciones de desarrollo.

Por otro lado, el estudio permite plantear el valor que tienen las alianzas, negociaciones y acuerdos, en tanto capacidades que legitiman el rol de brokers de las organizaciones no gubernamentales. La problemática de la tierra, como señaló Occhipinti (2005) para el caso de Fundapaz, es uno de los tópicos centrales desde los cuales las organizaciones fundamentan su actuación y su rol de mediadores. Los conocimientos que tienen las organizaciones sobre esta problemática han sido, y continúan siendo, un aspecto central de su autoridad como agentes de desarrollo local. 
A modo de cierre, interesa destacar que si bien es innegable la capacidad de influir y ejercer poder de las organizaciones no gubernamentales, también es cierto que su alcance en términos de transformación es limitado. Quizá una de las evidencias más claras en ese sentido es que sus acciones han escasamente logrado alterar e impedir el avance de medidas y políticas de un modelo de desarrollo productivista regional que atenta contra la propia definición de buen vivir de los pobladores locales, entendida como la posibilidad de tener el control sobre un proyecto de desarrollo propio.

\section{Anexo I. Sitios de consulta}

http://www.soniaescudero.com.ar

http://www.misereor.org/

http://www.fundapaz.org.ar

http://www.grupoclarin.com.ar/novedades/fundapaz40-anos

Fecha de recepción: 31 de enero de 2015 Fecha de aceptación: 20 de septiembre de 2015

Bibliografía

\section{6}


, y Rodríguez, H. (20I3). "Los bosques de Salta y el caso Pizarro como antecedente de una ley protectora", en M. Manzanal, y M. Ponce (orgs.), La desigualdad ¿del desarrollo? Controversias y disyuntivas del desarrollo rural en el norte argentino (pp. I7I-190). Buenos Aires: CICCUS. Camardelli, M. C., y Salazar, N. (20I3). "Territorio, ambiente y poder en la región chaqueña de la provincia de Salta", en M. Manzanal, y M. Ponce (orgs.), La desigualdad ¿del desarrollo? Controversias y disyuntivas del desarrollo rural en el norte argentino (pp. 19I-2I2). Buenos Aires: CICCUS. Carrasco, M. (2005). "Política indigenista del Estado democrático salteño entre 1986 y 2004", en C. Briones (comp.), Cartografias Argentinas. Políticas indigenistas y formaciones provinciales de alteridad (pp. 185-209). Buenos Aires: Antropofagia.

Castelnuovo, N. (20I3a). I. Registro personal de Trabajo de Campo: Mario, Embarcación, Salta, Argentina.

- (20I3b). 2. Registro personal de trabajo de campo: Carmen. Embarcación, Salta, Argentina. (20I3c). 3. Registro personal de trabajo de campo: Escudero. Embarcación, Salta, Argentina.

- (20I3d). 4. Registro personal de trabajo de campo: Susana. Embarcación, Salta, Argentina.

- (20/3e). 5. Registro personal de trabajo de campo: Claudia. Embarcación, Salta, Argentina.

- (20I3f). 6. Registro personal de trabajo de campo: Antonio. Embarcación, Salta, Argentina.

(20I3g). 7. Registro personal. Entrevista realizada a Enrique. Morillo, Salta, Argentina.

(20I3h). 8. Registro personal. Entrevista realizada a Martín. Ciudad de Salta, Argentina.

(20I5). Mujeres guaraníes y procesos de participación política en el noroeste argentino. Buenos Aires: Antropofagia. 
Bibliografía

Clarín (I 3 de enero de 20I4). "Por el desarrollo de las familias campesinas”. Diario El Clarín. Recuperado de: http:// www.grupoclarin.com.ar/novedades/fundapaz-40-anos

Dagnino, E. (20I I). "Civil Society in Latin America", en E. Michael (ed.), The Oxford Handbook of Civil Society (Pp. 122-133). Oxford: Oxford University Press.

De la Cruz, L. M. (1997). Y no cumplieron. Reflexiones acerca de la apasionada relación entre los organismos de promoción del desarrollo y los grupos wichí. Argentina: Proyecto DesarroIlo Agroforestal en Comunidades Rurales del Noroeste Argentino y Fundación para el Desarrollo Agroforestal de las Comunidades del Noroeste Argentino.

Declaración de la Mesa de la Tierra (2013). Argentina: Mesa de Tierra del Norte de Salta.

Escobar, A. (1998). La invención del Tercer Mundo. Construcción y deconstrucción del desarrollo. Bogotá: Norma.

Ferguson, J. (1997). The Anti-Politics Machine. Development, depoliticization and bureaucratic power in Lesotho. Minnesota: University of Minnesota Press.

Fisher, W. F. (1997). "Doing good? The Politics and Antipolitics of NGO Practices". Annual Review of Anthropology, 26, 439-464.

Fundapaz (2003). Informe: gestión de la propiedad de las tierras y conservación de los recursos naturales por comunidades indígenas y familias criollas. Los Blancos-Salta. Argentina: Fundapaz.

Gordillo, G., y Hirsch, S. (2003). "Indigenous Struggles and Contested Identities in Argentina". The Journal of Latin American Anthropology, 8(3), 4-30.

Lister, S. (2000). "Power in Partnership? An Analysis of an NGO's Relationships with its Partners". Journal of International Development, I2(2), 227-239.

Mendoza, M. (1994). "Organizaciones no gubernamentales indígenas en el Chaco Argentino". Revista de Antropología, (I5), 44-48. 
Mosse, D., y Lewis, D. (2006). "Theoretical Approaches Bibliografía to Brokerage and Translation in Development", en D. Lewis, y D. Mosse (eds.), Development brokers and translators: The ethnography of aid and agencies (PP. I-26). Bloomfield: KumarianPress.

Murtagh, R. (20I3). Experiencias y realizaciones de origen cristiano para afrontar la pobreza rural en el noroeste argentino, 1960-1983 (tesis doctoral inédita). Universidad Católica Argentina, Facultad de Ciencias Sociales, Políticas y de la Comunicación: Argentina.

Occhipinti, L. (2005). Acting on Faith: Religious Development Organizations in Northwest Argentina. Lanham: Lexington Books.

Olivier de Sardan, J. P. (2005). Anthropology and Development. Understanding contemporary social change. Londres/ Nueva York: ZedBooks.

Rodriguez Mir, J. (2006). "Resistencia y confrontación en Argentina. Negación y exclusión de los pueblos indígenas". Gazeta de Antropología, (22). Recuperado de: http:// www.ugr.es/ pwlac/G22_22Javier_Rodriguez_Mir.html (20II). "Transformando la alteridad. Alcances y limitaciones de los proyectos de desarrollo en las sociedades originarias del Chaco argentino". Gazeta de Antropología, 27(1), I-16.

Scardozzi, C. (2013). Territorios en negociación. Un análisis etnográfico de los procesos de convivencia entre indígenas y criollos en el Pilcomayo Salteño (Gran Chaco-Argentina). Serie Documentos. Argentina: Fundapaz.

Schmidt, M. (20I4). "Ordenadores y ordenados. Actores en disputa en el ordenamiento territorial de bosques nativos en la provincia de Salta". Cuadernos de Antropología, (I I), 37-55.

Spadafora, A. M. (2005). "Antropología, desarrollo y poblaciones endígenas. Una perspectiva crítica desde el Cono Sur", en O. Calavia, J. C. Gimeno, y M. E. Rodríguez 
Bibliografía (eds.), Neoliberalismo, ONG, pueblos indígenas en América Latina (pp. I07-I30). Málaga: SEPH.

Verbitsky, H. (2009). Vigilia de armas. Historia política de la Iglesia católica. Tomo III. Del Cordobazo de 1969 al 23 de 1976. Buenos Aires: Sudamericana. 